\title{
Acute Pancreatitis as a Complication of Sickle Cell Anaemia
}

\author{
Parisa L. Moori ${ }^{1, * \mathbb{D}}$, Alexios Dosis ${ }^{1}$, Zoheb Ahmad ${ }^{1}$, Ambareen Kausar ${ }^{1}$ and \\ Diana Triantafyllopoulou ${ }^{2}$ \\ 1 Department of General Surgery, Royal Blackburn Hospital, Haslingden Road, Blackburn, \\ England BB2 3HH, UK; alexios.dosis@doctors.org.uk (A.D.); zoheb.ahmad@doctors.org.uk (Z.A.); \\ Ambareen.kausar@elht.nhs.uk (A.K.) \\ 2 Department of Haematology, Royal Blackburn Hospital, Haslingden Road, Blackburn, \\ England BB2 3HH, UK; diana.triantafyllopoulou@elht.nhs.uk \\ * Correspondence: parisa.moori@elht.nhs.uk; Tel.: +44-1254263555
}

Received: 19 September 2018; Accepted: 23 October 2018; Published: 25 October 2018

\begin{abstract}
A common cause of abdominal pain is acute pancreatitis, with the majority of cases being attributed to gallstones and excess alcohol. Sickle cell anaemia (SCA) is an autosomal recessive disease causing the production of abnormal haemoglobin. Physiological changes can lead to vaso-occlusion in sickle cell anaemia. Cholelithiasis is frequently seen in patients with SCA and complications from this can increase patient morbidity. We present a rare case of acute pancreatitis inducing a vaso-occlusive crisis.
\end{abstract}

Keywords: acute pancreatitis; sickle cell anaemia; cholelithiasis; cholecystectomy

\section{Introduction}

Acute pancreatitis is one of the most common causes of acute abdominal pain necessitating hospital admission [1]. Gallstones and increased alcohol usage are the main aetiological factors contributing to the majority of cases [2]. In the UK alone, 26,000 hospital admissions a year are related to acute pancreatitis with an incidence of $\sim 56$ cases per 100,000 persons per year [3]. Sickle cell anaemia (SCA) is an inherited autosomal recessive disease which results in the production of haemoglobin $\mathrm{S}(\mathrm{HbS})$. The haemoglobin is distorted due to a point mutation in the beta globin gene [4]. If an individual's oxygen saturation is decreased during instances such as stress, infection, dehydration or lowered temperature, the distorted red blood cells (RBC) may cause vaso-occlusion and consequent tissue ischaemia [5]. Recent studies have highlighted the role of inflammation, endothelial dysfunction and coagulation in the early phase of acute pancreatitis. The severity of coagulopathy has been found to correlate with the severity of acute cases and serum levels of D-dimer and angiopoietin-2 have been found to be good predictors of severe acute pancreatitis [6]. We present a rare case of vaso-occlusive crisis (VOC) in a patient with SCA that was induced by acute pancreatitis. This case aims to raise awareness and provide education on the significance of considering the development of sickle cell crisis in patients presenting with acute pancreatitis or other acute abdomen.

\section{Case Report}

A 35-year-old female with a background of known gallstones and SCA requiring previous hospital admissions for vaso-occlusive crises, attended the emergency department. The patient presented with a 1-day history of severe right upper quadrant pain radiating to the back and associated nausea and vomiting. The pain was sharp in nature and worse on movement. Her observations in the department were as follows; temperature $37.7^{\circ} \mathrm{C}$, heart rate $110 \mathrm{bpm}$, blood pressure $130 / 80 \mathrm{mmHg}$, 
respiratory rate 20, saturating $98 \%$ on room air and Glasgow Coma Score (GCS) 15/15. On physical examination, she appeared jaundiced with scleral icterus. The patient had abdominal tenderness in the right hypochondrium and epigastric region, however no abdominal distension. There was no guarding, rigidity or rebound tenderness. Bowel sounds were audible. Cardiovascular, respiratory and neurological examinations were all unremarkable.

Intravenous access was obtained and blood tests taken. The patient was commenced on intravenous fluids, intravenous antibiotics and further analgesia before being admitted to the surgical triage unit. Initial blood results showed a haemoglobin $(\mathrm{Hb})$ of $108 \mathrm{~g} / \mathrm{L}$, which was around the patient's baseline. Bilirubin $185 \mu \mathrm{mol} / \mathrm{L}$, alanine transaminase (ALT) $301 \mathrm{IU} / \mathrm{L}$, alkaline phosphatase (ALP) $140 \mathrm{IU} / \mathrm{L}$, amylase $3308 \mathrm{IU} / \mathrm{L}$, c-reactive protein (CRP) $6 \mathrm{mg} / \mathrm{L}$, white blood cells (WBC) $16.9 \times 10^{9} / \mathrm{L}$ and lactate dehydrogenase (LDH) 1085 IU/L. Urea and electrolytes, calcium and lactate were all normal. The blood results in addition to the clinical picture demonstrated an obstructive jaundice and acute pancreatitis, possibly secondary to gallstones. The patient scored a 2 on the Glasgow score [7]. Shortly following admission, the patient was requiring oxygen with an increase in all over body pain and further pyrexia. Observations were as follows; temperature $40{ }^{\circ} \mathrm{C}$, heart rate $114 \mathrm{bpm}$, blood pressure $146 / 85$, respiratory rate 22 , saturating $100 \%$ on $4 \mathrm{~L}$ of oxygen. An ultrasound scan (USS) was obtained confirming acute pancreatitis with a dilated gallbladder containing dense debris and small calculi (Figures 1 and 2). The common bile duct (CBD) measured $7 \mathrm{~mm}$. Moderate pleural effusion on the right, small pleural effusion on the left. Repeat blood tests showed a $\mathrm{Hb}$ of $67 \mathrm{~g} / \mathrm{L}$, reticulocytes 3.4\%, bilirubin $307 \mu \mathrm{mol} / \mathrm{L}$, ALT $301 \mathrm{IU} / \mathrm{L}$, ALP $121 \mathrm{IU} / \mathrm{L}$, CRP $48 \mathrm{mg} / \mathrm{L}, \mathrm{WBC} 9.7 \times 10^{9} / \mathrm{L}$.

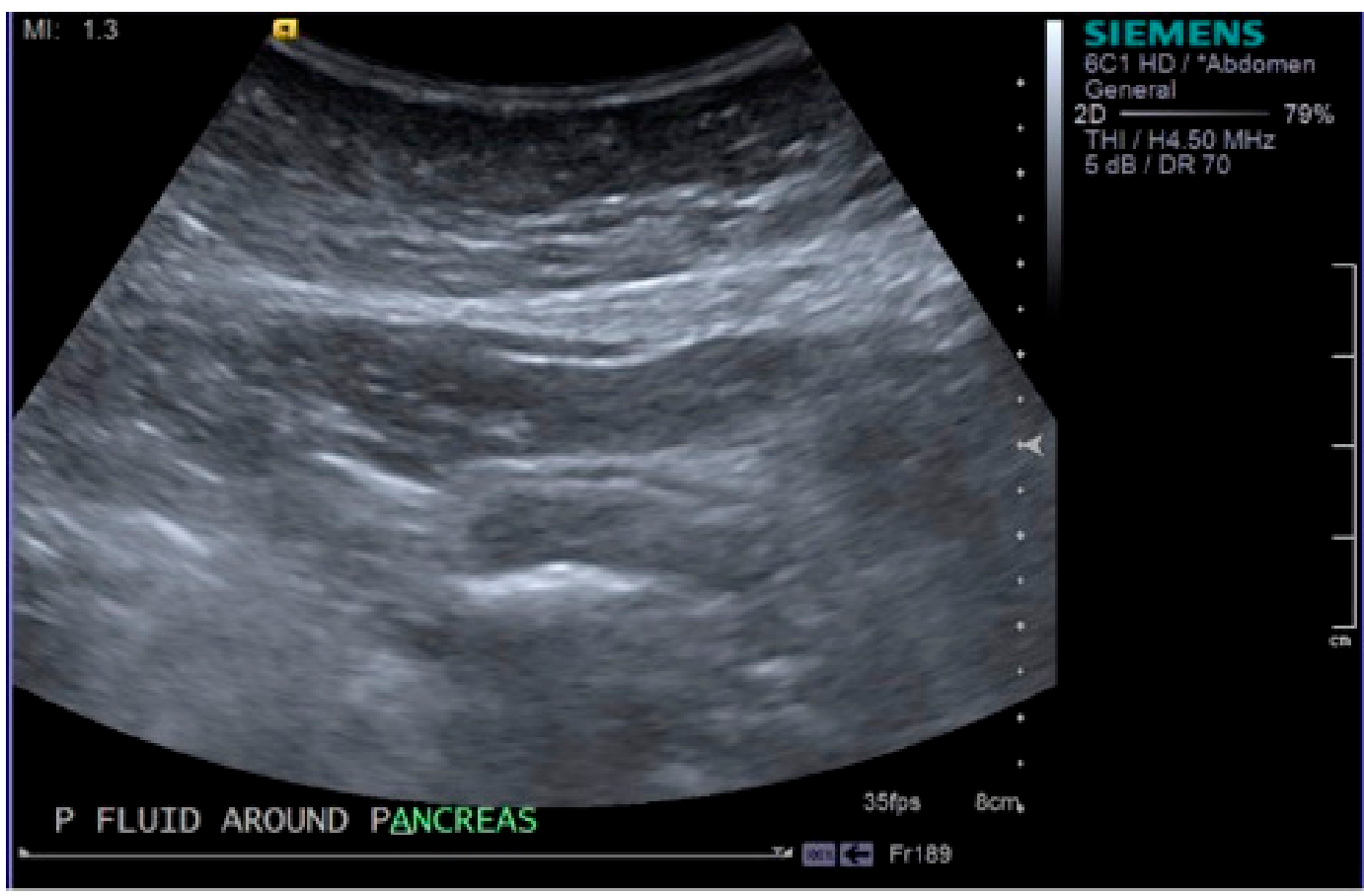

Figure 1. Image taken from the ultrasound scan demonstrating areas of fluid around the pancreas, confirming acute pancreatitis. 


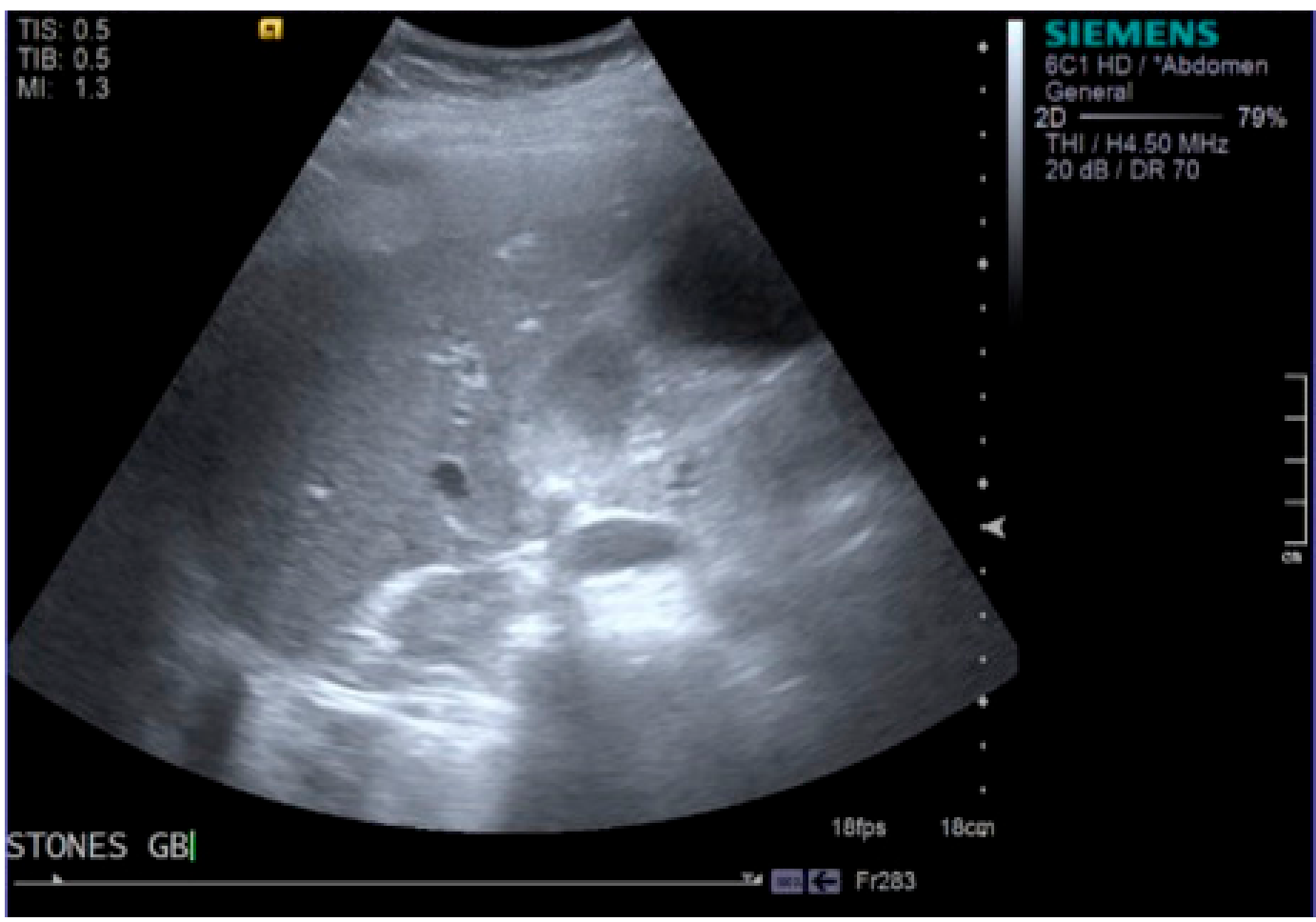

Figure 2. Image taken from the ultrasound scan showing the presence of gallstones within the gallbladder.

The patient was reviewed by haematology, confirming sickle cell crisis that was likely induced by acute pancreatitis. The antibiotics were switched to Ceftriaxone and the patient was transferred to the intensive care unit (ICU) for blood transfusions and pain management. Following a 3-day ICU stay, the patient underwent a magnetic resonance cholangio-pancreatography (MRCP) and subsequent laparoscopic cholecystectomy. No complications were encountered post-operatively and the patient did not require any further blood transfusions. She continued to improve and was discharged home.

Consent: Written informed consent was gained from the patient, giving approval to publish this information.

\section{Discussion}

The most common causes of acute abdominal pain in patients with SCA are acute cholecystitis, constipation secondary to opioids, hepatic and splenic sequestration, urinary tract infections and ischaemic bowel [8,9]. It is estimated that as many as $10 \%$ of patients with known SCA are admitted with acute abdominal pain every year. SCA is a common haemoglobinopathy which can affect multiple organ systems in the body. Within the digestive tract, the hepatobiliary system is most commonly affected in SCA. One of these manifestations is cholelithiasis, which is fairly common in patients with homozygous SCA, with an incidence of $26-58 \%$ in patients aged between $10-65$ [10]. There is still controversy around prophylactic cholecystectomy in asymptomatic SCA patients with known gallstones. The main reasons behind this uncertainty are due to the unknown natural history of the cholelithiasis and the undoubtedly higher surgical risk in this patient group. However, patients with sickle cell anaemia and gallstones became symptomatic in $75 \%$ of cases in comparison to $10 \%$ of the normal population, as shown by Al-Abkari et al. [11]. Abdominal pain is an important component of both acute pancreatitis and VOC in SCA. The majority of abdominal organs can be affected by SCA secondary to sickling, hypercoagulability, capillary engorgement and stasis [12]. Acute pancreatitis is a rare complication of VOC in SCA patients, however this case demonstrates a different aetiological 
picture; VOC as a complication of acute pancreatitis secondary to gallstones. This patient presented with accelerated haemolysis that had been associated with an acute painful episode.

Intravascular destruction of sickle erythrocytes is pathogenetically related to certain common complications of SCA. Haemolytic anaemia varies in intensity among the genotypes of SCA. Pulmonary hypertension, cerebrovascular events and priapism have been linked to haemolytic events [13]. Studies have shown that repetitive sickling/unsickling via cycles of deoxygenation/reoxygenation lead to a decrease in sickle red cell deformability that is associated with membrane loss and dehydration [14]. It is likely that in this case, the stress as a consequence of the pancreatitis may have led to a haemolytic crisis. In a 1988 study looking at pancreatitis in children, half of all of the patients in the study had an underlying haematological abnormality with the majority displaying SCA [15]. A case report from 1989 also describes a 51-year-old patient with acute pancreatitis during a VOC who subsequently developed a pancreatic pseudocyst, which was self-limiting with conservative management [16].

The variety of causes of acute abdomen in SCA patients presents a diagnostic challenge with there being such an overlap of clinical features. This is why clinical examination is so important along with the relevant blood tests and imaging. In addition to abdominal pain, our patient had elevated serum amylase and ultrasonographic evidence of acute pancreatitis and cholelithiasis. Subsequent MRCP also confirmed this. In the absence of any evidence of alcohol, drug or trauma-induced disease, this patient's issues were likely secondary to an obstructive aetiology. For this reason, we feel that prophylactic cholecystectomy should be considered for patients with SCA presenting with cholelithiasis.

\section{Conclusions}

Cholelithiasis is frequently seen in patients with SCA and any complications from cholelithiasis can radically increase these patients' morbidity. Therefore, prophylactic cholecystectomy should be considered for SCA patients with cholelithiasis who are at high risk of developing complications. It is important to remember that vaso-occlusive events can mask life threatening conditions that present with acute pain.

Conflicts of Interest: The authors declare no conflict of interest.

\section{References}

1. Forsmark, C.E.; Vege, S.S.; Wilcox, C.M. Acute Pancreatitis. N. Engl. J. Med. 2016, 375, 1972-1981. [CrossRef]

2. Lankisch, P.G.; Apte, M.; Banks, P.A. Acute pancreatitis. Lancet 2015, 386, 85-96. [CrossRef]

3. Shah, A.P.; Mourad, M.M.; Bramhall, S.R. Acute pancreatitis: Current perspectives on diagnosis and management. J. Inflamm. Res. 2018, 11, 77-85. [CrossRef] [PubMed]

4. Ware, R.E.; de Montalembert, M.; Tshilolo, L.; Abboud, M.R. Sickle cell disease. Lancet 2017, 390, $311-323$. [CrossRef]

5. Kato, G.J.; Steinberg, M.H.; Gladwin, M.T. Intravascular hemolysis and the pathophysiology of sickle cell disease. J. Clin. Investig. 2017, 127, 750-760. [CrossRef] [PubMed]

6. Dumnicka, P.; Maduzia, D.; Ceranowicz, P.; Olszanecki, R.; Drozdz, R.; Kusnierz-Cabala, B. The Interplay between Inflammation, Coagulation and Endothelial Injury in the Early Phase of Acute Pancreatitis: Clinical Implications. Int. J. Mol. Sci. 2017, 18, 354. [CrossRef] [PubMed]

7. Barreto, S.G.; Rodrigues, J. Comparison of APACHE II and Imrie Scoring Systems in predicting the severity of Acute Pancreatitis. World J. Emerg. Surg. 2007, 2, 33. [CrossRef] [PubMed]

8. Ahmed, S.; Siddiqui, A.; Siddiqui, R.; Kimpo, M.; Russo, L.; Mattana, J. Acute pancreatitis during painful sickle cell vaso-occlusive crisis. Am. J. Hematol. 2003, 73, 190-193. [CrossRef] [PubMed]

9. Hasan, B.; Asif, T.; Braun, C.; Bahaj, W.; Dosokey, E.; Pauly, R. Pancreatitis in the Setting of Vaso-occlusive Sickle Cell Crisis: A Rare Encounter. Cureus 2017, 9, 1193. [CrossRef] [PubMed]

10. Shah, R.; Taborda, C.; Chawla, S. Acute and chronic hepatobiliary manifestations of sickle cell disease: A Review. J. Gastrointest. Pathophysiol. 2017, 8, 108-116. [CrossRef] [PubMed]

11. Al-Abkari, H.; Abdulnabi, H.; Al-Jamah, A.; Meshikhes, A. Laparoscopic cholecystectomy in patients with Sickle Cell Disease. Saudi Med. J. 2001, 22, 681-685. [PubMed] 
12. Dhiman, R.; Yusif, R.; Nabar, U.; Albaqali, A. Gastrointestinal: Ischemic enteritis and sickle cell disease. J. Gastroenterol. Hepatol. 2004, 19, 1318. [CrossRef] [PubMed]

13. Kato, G.J.; Gladwin, M.T.; Steinberg, M.H. Deconstructing sickle cell disease: Reappraisal of the role of hemolysis in the development of clinical subphenotypes. Blood Rev. 2007, 21, 37-47. [CrossRef] [PubMed]

14. Presley, T.; Bain, L.; Ballas, S.; Nichols, J.; Sabio, H.; Gladwin, M.; Kato, G.T.; Kim-Shapiro, D. The Mechanism of Hemolysis in Sickle Cell Anemia. Blood 2008, 112, 1439.

15. Ziegler, D.W.; Long, J.A.; Philippart, A.I.; Klein, M.D. Pancreatitis in Childhood-Experience with 49 Patients. Ann. Surg. 1988, 207, 257-261. [CrossRef] [PubMed]

16. Kumar, A.; Posner, G.; Marsh, F.; Bellvue, R.; Dosik, H. Acute-Pancreatitis in Sickle-Cell Crisis. J. Natl. Med. Assoc. 1989, 81, 91-92. [PubMed]

(C) 2018 by the authors. Licensee MDPI, Basel, Switzerland. This article is an open access article distributed under the terms and conditions of the Creative Commons Attribution (CC BY) license (http:/ / creativecommons.org/licenses/by/4.0/). 